\title{
Revista de la
}

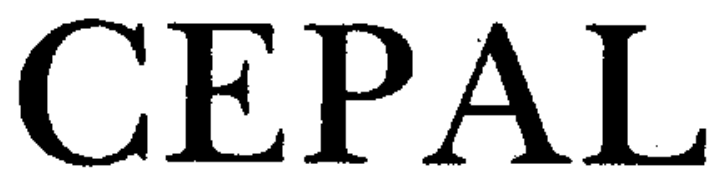

Secretario Ejecutivo

Gert Rosenthal

\section{Secretario Ejecutivo Adjunto}

Andrés Bianchi

\author{
Director de la Revista \\ Anibal Pinto \\ Secretario Técnico \\ Eugenio Lahera
}

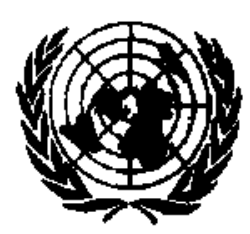

NACIONES UNIDAS

COMISION ECONOMICA PARA AMERICA LATINA Y EL CARIBE

SANTIAGO DE CHILE, DICIEMBRE DE 1989 


\section{Revista de la}

\section{CEPAL}

\section{SUMARIO}

E.l desarrollo de América Latina y el Caribe en los años ochenta y sus perspectivas.

Gert Rosenthal, Secretario Ejecutivo de la ciriat.

7

Características y fases del "modelo sueco". Olof Ruin.

Comentarios al texto del Profesor Olof Ruin. Adolfo Gurrieri.

Suecia y América Iatina: comentarios sobre el texto del Profesor Olof Ruin.

Francisco C. Weffort.

La incorporación de la mujer en las políticas de desarrollo. Cecilia López M. y Molly Pollack E. $\quad 39$

Una perspectiva del desarrollo social en Brasil. Sonia Miriam Draibe.

Tendencias de la integración en el mercado de trabajo brasileño. Claudio $S a l m$ y Laiz Carlos Eichenberg Silu's.

La iniciativa de los Estados Unidos para la cuenca del Caribe. Wilfred Whitingham.

El potencial tecnológico del sector primario exportador. Mikio Kuwayama.

10]

En torno a la integración económica argentino-brasileña. Daniel Chudnowsky y Fernando Porta.

125

E.l sistema centro-periferia y el intercambio desigual. Edgardo Floto.

147

Orientaciones para los colaboradores de la Revista de la cEPAi.

168

Publicaciones de la cripal. 


\section{Suecia y América Latina: comentarios sobre el texto del Profesor Olof Ruin}

Francisco C. Weffort*

Existe un "modelo sueco"? La expresión se utiliza varias veces en el texto del Profesor Olof Ruin. Quien habla de "modelo", admite la posibilidad de que proposiciones inspiradas en la experiencia histórica de uno o varios países puedan llegar a aplicarse a otro u otros países. Y quien conoce la historia del pensamiento y de la política latinoamericanos, sabe que, tomada en este sentido, la idea de un "modelo" puede suscitar reflexiones interesantes - a veces inquietantes- en las mentes latinoamericanas.

Por cierto que siempre se trata de una cuestión de perspectiva. Cada uno habla siempre a partir del lugar donde se halla. Así, en este caso consideraré siempre la descripción del Profesor Ruin sobre el desarrollo político de Suecia desde un punto de vista latinoamericano. ¿Existe un "modelo sueco" de desarrollo político para los latinoamericanos? Esta pregunta merece traducirse. ¿Qué es lo que los latinoamericanos pueden aprender de Suecia? ¿Qué es lo que deben considerar aplicable y qué inaplicable a nuestras circunstancias?

Dividiré mis comentarios en dos partes. En la primera, señalaré las diferencias históricas y estructurales entre lo que nos dice el Profesor Ruin sobre Suecia y lo que conocemos sobre América Latina. Me parece que esas diferencias desaconsejan la adopción de un "modelo sueco" por parte de los latinoamericanos (tal vez con la excepción de países como Costa Rica o Uruguay).

En la segunda parte, procuraré llamar la atención sobre las semejanzas. No son semejan-

*Profesor titular de la Universidad de Săo Paulo e inves. tigador del Centro de Estudios de Cultura Contemporánea (CEDEC).

El autor persigue reflejar en este articulo su participación en el Semisario sobre "Desarrollo, democracia y equidad: las experiencias de Suecia y América Latina", organizado conjuntamente por Ja División de Desarrollo Social de la ckrp y el Centro Internacional del Movimiento Obrero Sueco, Santiago de Chile, 29, 90 y 31 de mayo de 1989. zas en materia de experiencia histórica que permitan tomar a Suecia como "modelo". Prefiero tratarlas como convergencias, posibles semejanzas de orientación entre lo que ocurrió (y ocurre) en Suecia y to que con mucho esfuerzo y buena suerte puede llegar a ocurrir aquí. Son principios y orientaciones politicas de alcance general que, a mi juicio, deberíamos adoptar los latinoamericanos. En caso de haberlos ya adoptado, deberían ser afianzados por todos los latinoamericanos que busquen la consolidación de la democracia política, el desarrollo económico, la modernización cultural y social y una sociedad más justa y más libre.

\section{I \\ Las diferencias}

Me circunscribo a cinco puntos.

Primero: América Latina no tiene como Suecia una tradición parlamentarista la que, según el Profesor Ruin, contribuyó a propiciar en aquel país un desarrollo político más estable. Suecia es un país de tradición monárquica donde, sin embargo, el absolutismo fue siempre más moderado que en la mayoría de los paises europeos. El Profesor Ruin dice que desde mediados del siglo xvi "al lado del rey hubo siempre un parlamento". Ello obedeció a que pese a que el poder monárquico se volvió bastante fuerte durante la transición entre los siglos xvil y xviII, ya la constitución de 1809 habría de caracterizarse por "un equilibrio de poder entre el rey y el parlamento". A partir de entonces el parlamento cambia constantemente en el sentido de of recer los espacios institucionales para una creciente participación popular.

En cambio, América Latina tiene una tradi- 
ción presidencialista muy arraigada. Y muchos creen que el presidencialismo con su propensión plebiscitaria ha sido una fuente de inestabilidad política $y$, por tanto, de oportunidades para frecuentes recrudecimientos del autoritarismo en la región. En el siglo xIX $\longrightarrow$ que en Suecia es el periodo de consolidación de una tradición parlamentaria- estaban vigentes todavía en muchos países de América Latina las "autocracias unificadoras" de que hablaba Gino Germani. Y lo que viene después, désde las primeras décadas del siglo $\mathrm{xx}$, son los regímenes oligárquicos "de participación restringida", en todo caso muy distantes aún de las democracias parlamentarias europeas.

Segundo: Aquí hace falta el campesinado independiente que se desarrolla en Suecia desde comienzos del siglo $x i x$ y que encontró en el parlamento un espacio institucional para expresarse. Suecia, nos dice el Profesor Ruin, "nunca vivió períodos de abierta servidumbre feudal". En cuanto a América Latina, si bien ésta nunca fue feudal en el sentido europeo de la palabra, fue y sigue siendo señorial en muchos países. Somos el caso típico de un continente formado por la gran propiedad de la tierra con todas las consecuencias que eso acarrea para una estructura social basada en las relaciones de dependencia entre latifundistas y minifundistas, entre propietarios y trabajadores sin tierra.

La idea de una sociedad rural donde predominen la pequeña y la mediana propiedad generadoras de una clase media rural independiente, entendida como factor de estabilidad de la democracia, corresponde tal vez en el mejor de los casos a regiones dentro de algunos países. Lo que todavia predomina, en cambio, es el patrón de la gran propiedad, aunque esté en decadencia en muchas partes y esté sometida en otras a un intenso proceso de modernización. La reforma de la estructura agraria se inscribe dentro de los muchos tracasos de las políticas reformistas en América Latina.

Tercero: Suecia es el ejemplo del desarrollo de un liberalismo de contenido no sólo político (institucional) sino también social. En la descripción del Protesor Ruin se advierte que la alianza histórica - de comienzos de este siglo cuando se instaura en Suecia un régimen parlamentario moderno- entre la clase obrera representada por el Partido Socialdemócrata y los sectores so- ciales representados por el partido "de los liberales, actualmente llamado Partido Popular", no habría sido posible sin una condición ideológica favorable y que se expresa en la calidad social del liberalismo sueco.

En nuestro caso, el liberalismo es desde sus orígenes una ideología de los grandes propietarios de la tierra. Y se consolidó en la mayoría de los países como una ideología al estilo de los grandes propietarios, es decir, centrada rigurosamente en lo privado en el plano económico y social, muy formalista y juridicista en el plano político. En consecuencia, es totalmente ajeno a - la "cuestión social", o sea, a las reivindicaciones de la clase obrera y a los problemas sociales creados por el desarrollo del capitalismo, en particular, el de la industria. Según la expresión de algunos liberales descontentos con la rigidez de sus propias tradiciones de pensamiento, somos el caso típico de una historia política donde siempre anduvieron separadas las reivindicaciones de la libertad política y las de la igualdad social. O sea, aquí los liberales, sobre todo los con vinculaciones rurales, estuvieron casi siempre en contra de los intereses de los trabajadores industriales. Desde este punto de vista estamos en las antípodas de la experiencia sueca.

Cuarto: Suecia adquiere ya desde fines del siglo xix las características que deberían convertirla en un caso típico de "sociedad organizada". Partidos, iglesias, asociaciones (por ejemplo, la liga de los antialcohólicos) - - en la Suecia de fines del siglo pasado se perfilan ya los rasgos de la Suecia de hoy. Es una sociedad de grupos organizados e independientes los que por eso mismo se revelan capaces de convivir y de establecer pactos entre sí. Además de las alianzas políticas entre obreros y campesinos ( $y$ entre socialistas y liberales), esta capacidad de establecer pactos se revela en el acuerdo de Saltsjobaden celebrado en 1938, con el que se inicia un período de convivencia armónica duradera entre empleados y empleadores.

En América Latina, las relaciones sociales y políticas que han predominado desde fines del siglo xix nos definen como sociedades formadas por grupos sociales dotados de una baja capacidad de organización e independencia. Por ejemplo, desde el punto de vista de la historia social y politica de los trabajadores, la experiencia típica de los latinoamericanos parece evolucionar des- 
de la dependencia hacia el conflicto. Vamos desde los fenómenos de dependencia de masas, ejemplificados por nuestros diversos populismos en los que la cooperación entre las clases se da a costa de la autonomfa de los de abajo, hasta afirmar la independencia de las mismas en las luchas sociales.

El aumento de nuestra capacidad de organización acrecienta en vez de disminuir nuestra capacidad para el conflicto. Puede que el mismo raciocinio sea válido para otros sectores sociales, por ejemplo, el empresariado industrial o los banqueros. Es decir, cuanto más nos organizamos más difíciles se tornan los pactos. Tal vez esta relación entre capacidad de organización y capacidad de conflicto cambie de signo en el futuro, y propicie un terreno nuevo de "concertación" entre las clases. Pero, debe tratarse de un futuro muy distante, pues seria ilusorio imaginarse que esta posibilidad se encuentre a la vuelta de la esquina.

También se puede pensar a título especulativo que de andar bien las cosas en materia de democracia política en el futuro, nos aproximaríamos más a un "modelo" estadounidense de sociedad -o sea, conflicto e independencia en el plano económico y social, garantías de igualdad en el plano político-institucional-que a un "modelo" europeo socialdemócrata. Pero como aquí las cosas no siempre se dan bien en el plano de la democracia política, los conflictos generados por situaciones de extrema desigualdad so- cial, crisis económicas, etc., corren el riesgo de transformarse directamente en violencia de masas y en represión estatal también en gran escala.

Este es el problema: no somos una "sociedad organizada" como Suecia ni una democracia consolidada como Estados Unidos. Si en la cultura estadounidense se dice que el precio de la libertad es la vigilancia que ejercen los ciudadanos sobre el Estado, aquí el precio de la independencia de los grupos sociales parece ser la desconfianza en relación con los demás grupos sociales. Ningún lector de Hobbes debería extrañarse si esta guerra de "todos contra todos" en una sociedad civil carente del amparo de una democracia política fuerte, sirve para pavimentar el camino del Leviatán estatal autoritario.

Quinto: En los comienzos históricos y sociales de la implantación del régimen parlamentario y después de la Socialdemocracia, se registra en Suecia una emigración extraordinaria que llega a cerca del $20 \%$ de la población. Esa "sobrepoblación relativa" que no podía integrarse a los patrones de la sociedad moderna que se construía entonces, halló posibilidades de incorporarse en otros paises, en especial en los Estados Unidos. La mayor parte de los países de América Latina se caracterizan por una "sobrepoblación relativa" que simplemente no tiene ningún otro lugar donde ir. ¿Cómo puede "organizarse" una sociedad cuyo funcionamiento "normal" presupone la exclusión de masas tan considerables de la población?

II

\section{Las convergencias}

Las semejanzas, como ya señalé, se encuentran no tanto en la experiencia histórica como en los principios de comportamiento y orientaciones políticas de carácter general. Deseo mencionar aquí cuatro puntos de posibles convergencias.

Primero: El desarrollo moderno de Suecia obedece a una secuencia histórica sumamente atrayente desde el punto de vista de los demócratas y socialistas latinoamericanos. Estamos saliendo de un largo período de dictaduras militares cuyos tecnócratas quisieran acostumbrarnos a la teoria según la cual seria necesario esperar que primero creciera la torta para redistribuirla después. Lo triste del caso es que a pesar de esa teoría y de las dictaduras que la inspiraban, en varios paises simplemente no se creció. En otros se creció poco. E incluso en aquellas situaciones en que se creció mucho, no hubo redistribución en la práctica.

Hoy se asiste en la mayoría de los países a una situación de estancamiento que exige buscar nuevas perspectivas de crecimiento. En tales cir- 
cunstancias, el caso sueco es sumamente inspirador. Sugiere que es posible crecer y redistribuir. Aunque se sabe que Suecia contó en diversas oportunidades con circunstancias económicas favorables, las que faltan precisamente en las actuales condiciones latinoamericanas, la experiencia sueca de crecer y redistribuir al mismo tiempo sugiere la idea de que la redistribución, en vez de ser sólo el efecto puede ser también la causa del crecimiento.

Segundo: El desarrollo moderno de Suecia comienza con la democracia política, le sigue la democracia social y, por último, se espera que venga la democracia económica. O sea, primero las instituciones políticas (parlamento, partidos, etc.), después los derechos sociales (Welfare State) y la política económica distributiva y, por último, cambios de la estructura productiva encaminados a una democratización de la vida económica (por ejemplo, fondo de los asalariados). Es en el campo de aquello que se denomina democracia económica que se inscribirían las cuestiones relativas a la socialización de la producción.

Pese a todo lo esquemático de esta secuencia -cosa que se advierte, por lo demás, en estos comentarios desde las primeras palabras- ella representa algún elemento de verosimilitud con las situaciones que hoy viven diversos paises latinoamericanos. Aunque el tema del socialismo se encuentre presente en el debate latinoamericano, lo cierto es que la democratización de la economía en el sentido ya descrito se halla fuera del alcance de la mayor parte de nuestros países.

Pero también es cierto que en la América Latina de hoy, como en la Suecia de comienzos de siglo, el punto de partida es la democracia politica. Del mismo modo, se sabe que el próximo paso en América Latina - y que tiene que darse dentro de poco si creemos en la necesidad de consolidar la democracia política- es el de la democracia social, lo que significa precisamente la consolidación y ampliación de los derechos sociales y la conquista de una política económica distributiva. Desde el ángulo de la secuencia democracia polírica-democracia social, la experiencia de Suecia asume un carácter ejemplar pese a todas las diferencias ya mencionadas y cualquiera que sea nuestro concepto respecto a las posibilidades futuras de una democratización (o socialización) económica.

Tercero: También en el campo de los actores y las fuerzas sociales que protagonizan estos cambios, América Latina puede llegar a encontrar un punto de aproximación con la experiencia sueca. A diferencia de otros países europeos que se apoyaron más en sus burguesías y sus clases medias, el desarrollo democrático de Suecia se apoyó fundamentalmente en la clase obrera industrial y en el campesinado. O sea, en aquello que en América Latina incluimos en la designación genérica de "clases populares".

Por lo que se conoce de la experiencia historica de países como Uruguay, Argentina, Brasil, Chile y México, parece claro que el futuro reserva a las clases populares un papel fundamental en el desarrollo y la democratización de América Latina. Estamos en una región en la que, según la clásica formulación de Weber, las clases tradicionales ya no son capaces de dirigir la sociedad. Y aunque también puede afirmarse que los trabajadores y en general las "clases populares" aún no son capaces de hacerlo, parece que se aproximan a ello en la medida en que avanza la modernización y se consolida la democracia política. Incluso porque la modernización y la democratización política vienen sirviendo en la mayoría de nuestros paises para denunciar las insuficiencias de nuestras burguesías industriales concebidas (o)mo clases nacionales. A diferencia de las clases portadoras de proyectos de importancia para el conjunto de las sociedades nacionales en que ellas mismas existerı, nuestras burguesías industriales parecen más aptas para beneficiarse del Estado que para dirigirlo.

Cuarto: Last but not least, una anotación sobre un aspecto cultural que puede adquirir carácter decisivo en relación con las posibilidades de desarrollo de la democracia y de los progresos de la igualdad en América Latina. Suecia es el ejemplo victorioso de una cultura política que cree en la posibilidad de las reformas, es decir, que cree en la posibilidad de cambiar gradualmente la sociedad. El tema del significado de las reformas es hoy un tema decisivo para el futuro de América Latina.

Después de mucho desconfiar de las reformas, muchos latinoamericanos vinieron a valorizar en un período reciente, y por lo demás durísimo, los "pequeños avances". 'Toda una cultura política acostumbrada a la idea - de tendencia globalizante pero a veces de inclinación totalitaria- de que todo tiene que cambiar fo de lo 
contrario no se consigue cambiar nada), fue llevada por la fuerza de las cosas a admitir que incluso un pequeño cambio es mejor que ninguno. Puede que la percepción de ello nos aproxime más al sentido de la experiencia sueca que a un "modelo" determinado.

Tal vez eso se llame en Suecia pragmatismo. Aquí en América Latina la valorización de los "pequeños avances" tiene un sentido dramático que debe ser bien entendido. Más que el elemento de cálculo y el grado de cinismo que habitualmente se reconoce en el pragmatismo, una política de reformas se debe fundamentar en la convicción de que no sólo no se puede avanzar de otro modo, sino que tal vez no se consiga sobrevivir de otro modo. Para los que tuvieron que luchar contra el terror de Estado se aclararon varias cuestiones que antes eran oscuras. Por ejemplo, quedó en claro que el habeas corpus es un "pequeño avance" esencial. Así, les fue más fácil entender que en paises en que millones y millones de personas viven en situaciones de extrema pobreza las respuestas para los problemas inmediatos, por "pequeños" que sean, pueden ser la diferencia que existe entre la vida y la muerte. Nacida de grandes derrotas históricas de la democracia y de los trabajadores de América Latina, la convicción que fundamente en América Latina una politica de reformas debe significar el renacer de la esperanza para aquellos que parecian definitivamente condenados a no tener esperanza alguna.

En vez de un nuevo pragmatismo, tal vez las condiciones dramáticas de América Latina creen una nueva base moral para establecer una politica de reformas. Pese a que nada sabía de la historia sueca, en este aspecto estoy convencido de que los socialistas y los demócratas latinoamericanos se hallan muy próximos a la situación que vivian los socialistas y los demócratas de Suecia durante la transición del siglo xIX al $\mathrm{xx}$ y a todos los que son capaces de entender el sentido de su lucha. Fueron ellos la fuente de un "nuevo comienzo" para la historia humana en aquella parte del mundo. Y es eso precisamente lo que se trata de hacer aquí.

(Traducido del portugués) 